\title{
Thinking Outside the Silicon Box: Molecular AND Logic As an Additional Layer of Selectivity in Singlet Oxygen Generation for Photodynamic Therapy
}

\author{
Suriye Ozlem ${ }^{\dagger}$ and Engin U. Akkaya ${ }^{*, \neq}$ \\ Department of Chemistry, Middle East Technical University, TR-06531, Ankara, Turkey, and Department of \\ Chemistry and UNAM-Institute of Materials Science and Nanotechnology, Bilkent University, 06800 Ankara, Turkey
}

Received October 27, 2008; E-mail: eua@fen.bilkent.edu.tr

Following a highly influential paper by de Silva, ${ }^{1}$ there have been many reported examples of individual molecular logic gates, ${ }^{2}$ and molecular equivalents of even more complex digital designs were presented in recent years, such as half adder, ${ }^{3}$ half-subtractor ${ }^{4}$ and multiplexer. ${ }^{5}$ Nevertheless, the unresolved issues of individual addressability and input-output heterogeneity remain to be important handicaps, making molecular logic gates very difficult to integrate for the implementation of more advanced digital operations. However, in recent years, there have been important advances toward finding practicality in molecular logic gates, such as, identification tags for small objects, ${ }^{6}$ molecular keypad lock, ${ }^{7}$ laboratory on molecule, ${ }^{8}$ and pro-drug activation. ${ }^{9}$ RNA-based logic devices were also shown to be promising in vitro, yielding fluorescent proteins,${ }^{10}$ or potentially important DNA antisense drug sequences as outputs. ${ }^{11}$

In this Communication, we will put forward the idea that in essence, a comparison between the silicon-based digital electronics and "chemical" logic gates is mostly unfair, chemical logic systems are inherently more capable than they are given credit for, and the potential of the chemical logic gates is yet largely untapped. The chemical logic gates and the biomolecules in living systems, including ourselves, speak the same language. It may be challenging to integrate two molecular logic gates; however, they can be easily integrated into the control processes of healthy or pathological biochemistry.

Photodynamic therapy is a noninvasive methodology used for the treatment malignant tumors and age related macular degeneration. The treatment requires a combined application of red to near IR light and a sensitizer. The cytotoxic agent thus produced within the target region is singlet oxygen.

A few years ago, O'Shea published ${ }^{12}$ a report, where it was shown that singlet oxygen generation rate could be modulated by $\mathrm{pH}$. This effect is directly related to PET efficiency; excited-state molecules can relax through a number of different pathways including two competing processes, intersystem crossing and photoinduced electron transfer. Blocking of PET process by protonation of the amine PET donor, shuts down one channel of deactivation, and thus enhances intersystem crossing efficiency and the rate of singlet oxygen generation.

Recent works by Nagano ${ }^{13}$ and us $^{14}$ have demonstrated that appropriately decorated bodipy ${ }^{15}$ dyes can be very efficient generators for singlet oxygen, and thus act as satisfactory photodynamic agents. As a bonus, the dyes synthesized in our laboratory absorbed very strongly at $660 \mathrm{~nm}$ which is considered to be well within the therapeutic window of mammalian tissue. We are aware of the fact that PET process can be manipulated by a large variety of modulators other than $\mathrm{pH}$ : cations, anions, carbohydrates, phos-

\footnotetext{
Middle East Technical University.

* Bilkent University.
}

phates, among others. ${ }^{16}$ So, combining our earlier experience in molecular logic gates and rational design of photodynamic agents, we proposed a photodynamic therapy agent that would release singlet oxygen at a much larger rate when two cancer related cellular parameters are above a threshold value within the same spatiotemporal coordinates. Thus, the proposed logic gate would be actually an AND logic gate, the output of which would be singlet oxygen. Following a survey of the relevant literature for cancer related cellular parameters, we decided that $\mathrm{Na}^{+}$and $\mathrm{H}^{+}$concentrations $(\mathrm{pH})$ could be very promising targets. In the tumor tissues, the $\mathrm{pH}$ can be quite acidic, especially in the intracellular large acidic vacuoles (LAV) it can drop below $4,{ }^{17}$ and intracellular sodium ion concentration is also significantly higher (up to three times) than normal tissues. ${ }^{18}$ Thus, in the proposed logic system the chemical inputs are $\mathrm{Na}^{+}$and $\mathrm{H}^{+}$. The molecular system is in fact an automaton which is to seek higher concentration of both hydrogen and sodium ions, and release the cytotoxic agent (singlet oxygen) only when both concentrations are high. The design for the automaton includes the following elements: (i) strong long wavelength absorption, preferably beyond $650 \mathrm{~nm}$; 3,5-distyryl substituted bodipy dyes are useful in this regard with typical absorption peaks ranging from $630-720 \mathrm{~nm}$; (ii) an acid sensitive absorption peak; we reasoned this could be best achieved by incorporating dimethylaminostyryl or pyridylethenyl moieties; (iii) in order to modulate PET efficiency and intersystem crossing efficiency which is directly related to the PET process we utilized a crown-ether-based PET modulator which is only sensitive to sodium but not to hydrogen ions. With these design considerations, we set out for the synthesis of compound $\mathbf{1}$.

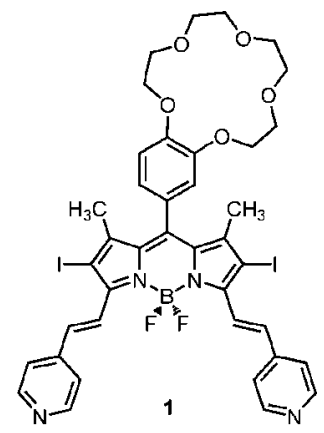

The synthesis starts with the formylation of benzo[15]-crown-5. Then, using standard procedures and the resulting aldehyde, together with 2,4-dimethylpyrole a bodipy dye was obtained. To facilitate intersystem crossing, 2 and 6 positions of the boradiazaindacene ring system were iodinated with iodic acid-iodine mixture. ${ }^{13}$ Acid sensitivity conferring pyridyl groups were appended by a 2-fold Knoevenagel reaction of 3 and 5 methyl substituents on the bodipy core and 4-pyridylcarboxyaldehyde. ${ }^{19}$ 


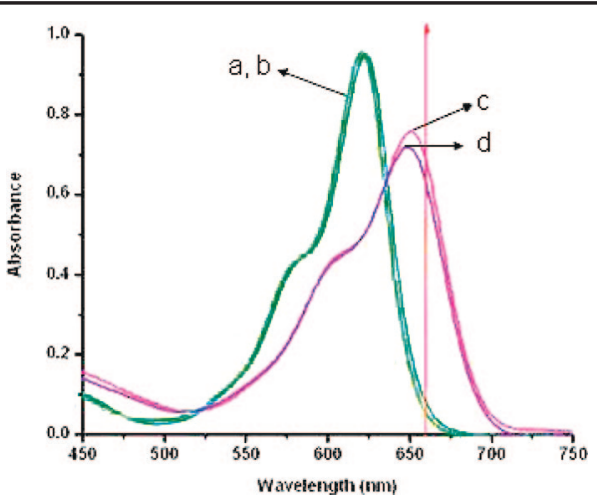

Figure 1. Spectral changes in acetonitrile solution of the compound $\mathbf{1}$ (2.0 $\times 10^{-5} \mathrm{M}$ ) in response to added modulators: (a) no added modulators, (b) $\mathrm{Na}^{+}$, (c) TFA, (d) $\mathrm{Na}^{+}$and TFA. The vertical line corresponds to the wavelength $(660 \mathrm{~nm})$ of LED excitation in the singlet oxygen generation experiments.

Table 1. Relative Efficiencies of Singlet Oxygen Generation by the Photosensitizer 1

\begin{tabular}{|c|c|c|}
\hline \multicolumn{2}{|c|}{ input $^{a}$} & \multirow{2}{*}{$\frac{\text { output }^{b}}{{ }^{1} \mathrm{O}_{2}}$} \\
\hline $\mathrm{Na}^{+}$ & $\mathrm{H}^{+}$ & \\
\hline 0 & 0 & low (1.0) \\
\hline 1 & 0 & low (2.9) \\
\hline 0 & 1 & low $(1.0)$ \\
\hline 1 & 1 & high (6.1) \\
\hline
\end{tabular}

${ }^{a}$ For $\mathrm{Na}^{+}$input $=1$, sodium ion concentration was set to $1.0 \mathrm{mM}$. For $\mathrm{H}^{+}$input $=1$, TFA concentration was set to $0.1 \mathrm{mM} .{ }^{b}$ Relative rates of singlet oxygen production in isopropyl alcohol was determined by the degradation of the trap molecule 1,3-diphenylisobenzofuran (100 $\mu \mathrm{M})$.

Spectral characteristics and singlet oxygen generation capacity of compound $\mathbf{1}$ were studied in acetonitrile. When a small aliquot of TFA was added to acetonitrile solution of $\mathbf{1}$, a red shift in the absorption spectra was observed moving the absorption peak value from 630 to $660 \mathrm{~nm}$ (Figure 1). We have also demonstrated that this shift is produced only when acid was added, and even large sodium concentrations did not cause any spectral shifts. The excitation source of our choice was an LED array with peak irradiation at $660 \mathrm{~nm}$. This means that the dye 1 would be most efficiently excited under acidic conditions to generate singlet oxygen, because only when pyridine groups are protonated, does the compound become strongly absorbing at $660 \mathrm{~nm}$ as a result of protonation-induced bathochromic shift.

Relative rates of singlet oxygen generation were determined using 1,3-diphenyl-isobenzofuran as a trap molecule. The results are shown in Table 1. Thus, using $660 \mathrm{~nm}$ LED source maximum rate of singlet oxygen generation were observed when both TFA and $\mathrm{Na}^{+}$ions were present. When neither TFA nor $\mathrm{Na}^{+}$were present or when only TFA was present, a significantly lower rate of production is in effect. $\mathrm{Na}^{+}$alone results in a somewhat higher rate than the reference state (both inputs $=0$ ) demonstrating strong reciprocal relationship between PET and intersystem crossing processes at least for this molecule. This experimental results are in accordance with AND logic operation. We also wanted to eliminate nonspecific ionic strength related effects as a cause for the faster rate of singlet oxygen generation in $1.0 \mathrm{mM} \mathrm{Na}^{+}$solutions. When $\mathrm{Cs}^{+}$salt (chloride) was added at the same concentration instead of $\mathrm{Na}^{+}$, the rate of singlet oxygen production was not altered, it was the same as the reference rate.

$\mathrm{Cs}^{+}$does not have a particular affinity for the smaller crown ether moiety, so $\mathrm{Cs}^{+}$addition is not expected to modulate PET process.
In conclusion, the compound $\mathbf{1}$ is a prototypical example of an automaton which would release its lethal weapon following an evaluation of the endogenous cellular parameters for signs of disease, and when necessary and sufficient conditions are met. This prototype also points to the direction of further development; incorporation of additional functional units which modulate singlet oxygen generation efficiency could result in therapeutic agents with a very high level of selective delivery potential. The notion of molecular logic gates assisted us in the design of this particular PDT agent and it is very likely molecular medicine could be the first niche application of molecule-based logic gates. The molecular automaton described here, combines sensing, computing, and actuating functions within a single molecule. While we appreciate the fact that the acidity and ion concentrations used in this proofof-principle study is too high to have direct biological consequence, this work demonstrates how, when liberated from the boundaries of silicon-dominated digital world, we might start to appreciate the true potential of the molecular electronics.

Acknowledgment. The authors gratefully acknowledge support from Turkish Academy of Sciences.

Supporting Information Available: Synthesis procedures, additional spectral data, ${ }^{1} \mathrm{H}$ and ${ }^{13} \mathrm{C}$ NMR spectra, HRMS data. This material is available free of charge via the Internet at http://pubs.acs.org.

\section{References}

(1) de Silva, A. P.; Gunaratne, H. Q. N.; McCoy, C. P. Nature 1993, 364, $42-44$.

(2) Recent reviews: (a) Pischel, U. Angew Chem., Int. Ed 2007, 46, 40264040. (b) de Silva, A. P.; McClenaghan, N. D. Chem.-Eur. J. 2004, 10, 574-586. (c) Szacilowski, K. Chem. Rev. 2008, 108, 3481-3548. (d) de Silva, A. P.; Uchiyama, S. Nat. Nanotechnol. 2007, 2, 399-410.

(3) de Silva, A. P.; McClenaghan, N. D. J. Am. Chem. Soc. 2000, 122, 39653966. (b) Margulies, D.; Melman, G.; Felder, C. E.; Arrad-Yellin, R.; Shanzer, A. J. Am. Chem. Soc. 2004, 126, 15400-15401. (c) Kou, S.; Lee, H. N.; van Noort, D.; Swamy, K. M. K.; Kim, S. H.; Soh, J. H.; Lee, K.-M.; Nam, S.-W.; Yoon, J.; Park, S. Angew. Chem., Int. Ed. 2008, 48, $872-876$.

(4) (a) Langford, S. J.; Yann, T. J. Am. Chem. Soc. 2003, 125, 11198-11199. (b) Coskun, A.; Deniz, E.; Akkaya, E. U. Org. Lett. 2005, 7, 5187-5189.

(5) (a) Andreasson, J.; Straight, S. D.; Bandyopadhyay, S.; Mitchell, R. H.; Moore, T. A.; Moore, A. L.; Gust, D. Angew. Chem., Int. Ed. 2007, 46, 958. (b) Amelia, M.; Baroncini, M.; Credi, A. Angew. Chem., Int. Ed. 2008, 47, 6240-6243.

(6) de Silva, A. P.; James, M. R.; McKinney, B. O. F.; Pears, P. A.; Weir, S. M. Nat. Mater. 2006, 5, 787-790.

(7) Margulies, D.; Felder, C. E.; Melman, G.; Shanzer, A. J. Am. Chem. Soc. 2007, 129, 347-354

(8) Magri, D. C.; Brown, G. J.; McClean, G. D.; de Silva, A. P. J. Am. Chem. Soc. 2006, 128, 4950-4951.

(9) Amir, R. J.; Popkov, M.; Lerner, R. A.; Barbos, C. F.; Shabat, D. Angew. Chem., Int. Ed. 2005, 44, 4378-4381.

(10) (a) Win, M. N.; Smolke, C. D. Science 2008, 322, 456-460. (b) Rinaudo, K.; Bleris, L.; Maddemsetti, R.; Subramanian, S.; Weiss, R.; Benenson, Y. Nat. Biotechnol. 2007, 25, 795-801.

(11) Benenson, Y.; Gil, B.; Ben-Dor, U.; Adar, R.; Shapiro, E. Nature 2004, 429, 423-429.

(12) McDonnel, S. O.; Hall, M. J.; Allen, L. T.; Byrne, A.; Gallagher, W. M.; O'Shea, D. F. J. Am. Chem. Soc. 2005, 127, 16360-16361.

(13) Yogo, T.; Urano, Y.; Ishitsuka, Y.; Maniwa, F.; Nagano, T. J. Am. Chem. Soc. 2005, 127, 12162-12163.

(14) Atilgan, S.; Ekmekci, Z.; Dogan, A. L.; Guc, D.; Akkaya, E. U. Chem. Commun. 2006, 4398-4400.

(15) (a) Ulrich, G.; Ziessel, R.; Harriman, A. Angew. Chem., Int. Ed. 2008, 47, 1184-1201. (b) Ziessel, R.; Ulrich, G.; Harriman, A. New J. Chem. 2007, 31, 496-501. (c) Loudet, A.; Burgess, K. Chem. Rev. 2007, 107, 48914932.

(16) De Silva, A. P.; Gunaratne, H. Q. N.; Gunnlaugsson, T.; Huxley, A. J. M.; McCoy, C. P.; Rademacher, J. T.; Rice, T. E. Chem. Rev. 1997, 97, 15151566.

(17) Montcourrier, P.; Mangeat, P. H.; Valembois, C.; Salazar, G.; Sahuquet, A.; Duperray, C.; Rochefort, H. J. Cell Sci. 1994, 107, 2381-2391.

(18) Cameron, I. L.; Smith, N. K. R.; Pool, T. B.; Sparks, R. L. Cancer Res. 1980, 40, 1493-1500.

(19) Dost, Z.; Atilgan, S.; Akkaya, E. U. Tetrahedron 2006, 62, 8484-8488. 